\title{
An experimental study of high heat flux removal by shear-driven liquid films
}

\author{
Dmitry Zaitsev ${ }^{1,2}$, Egor Tkachenko ${ }^{1,2}$ and Oleg Kabov ${ }^{1,2}$ \\ ${ }^{1}$ Institute of Thermophysics SB RAS, Novosibirsk, Russia \\ ${ }^{2}$ Novosibirsk State University, Novosibirsk, Russia
}

\begin{abstract}
Intensively evaporating liquid films, moving under the friction of a co-current gas flow in a mini-channel (shear-driven liquid films), are promising for the use in cooling systems of modern semiconductor devices with high local heat release. In this work, the effect of various parameters, such as the liquid and gas flow rates and channel height, on the critical heat flux in the locally heated shear-driven water film has been studied. A record value of the critical heat flux of $1200 \mathrm{~W} / \mathrm{cm}^{2}$ has been achieved in experiments. Heat leaks to the substrate and heat losses to the atmosphere in total do not exceed $25 \%$ for the heat flux above $400 \mathrm{~W} / \mathrm{cm}^{2}$. Comparison of the critical heat fluxes for the shear-driven liquid film and for flow boiling in a minichannel shows that the critical heat flux is an order of magnitude higher for the shear-driven liquid film. This confirms the prospect of using shear-driven liquid films in the modern high-efficient cooling systems.
\end{abstract}

\section{Introduction}

Development of the modern microelectronic equipment requires the effective cooling solutions because it is necessary to remove high heat fluxes of up to $1 \mathrm{~kW} / \mathrm{cm}^{2}$ and higher from the local hot spots of the processor [1]. Thin and ultra-thin (less than $10 \mu \mathrm{m}$ in thickness) liquid films, moving under the action of a forced gas flow in a mini-channel, are promising for the use in the temperature control systems of modern semiconductor devices [2]. The numerical and analytical studies of the heat and mass transfer processes and hydrodynamics of joint motion of intensively evaporating liquid film and gas flow in a mini-channel have been performed in [3-4]. The authors of [5-7] have determined the basic laws of the flow and crisis phenomena in the liquid film, moving under the influence of a gas flow in a horizontal channel, under moderate heat fluxes. The first experiments with locally heated liquid films, moving under the action of gas, showed that they are less subject to the breakdown than the liquid films moving under action of gravity. This is because the film breakdown and formation of dry spots can be controlled by the forced gas flow. Liquid film breakdown and formation of dry spots are important for studying the crisis phenomenon in the liquid films [8-9]. The main goal of this work is to study the breakdown and critical heat flux in the locally heated shear-driven films of water. Experimental data on removal of the heat fluxes higher than $1 \mathrm{~kW} / \mathrm{cm}^{2}$ from a heat source of $1 \mathrm{x} 1 \mathrm{~cm}^{2}$ are presented in the paper. Data on heat leakages into the substrate and heat losses into the atmosphere are also presented here. 


\section{Experimental setup}

The working section construction is shown in Fig. 1. Its main part is a stainless-steel plate with an embedded copper rod. The rod has a shape of a square head of $1 \times 1 \mathrm{~cm}^{2}$. The rod is heated by a spiral, wound on its bottom part (not shown in Fig. 1). This construction of the heater ensures a constant temperature along the rod surface (this is proved by the measurements of thermocouples). The working section is covered by a transparent optical glass (not shown in Fig. 1) to form a flat channel. The channel width is $40 \mathrm{~mm}$, while the channel height can be varied from 0.15 to $2 \mathrm{~mm}$.

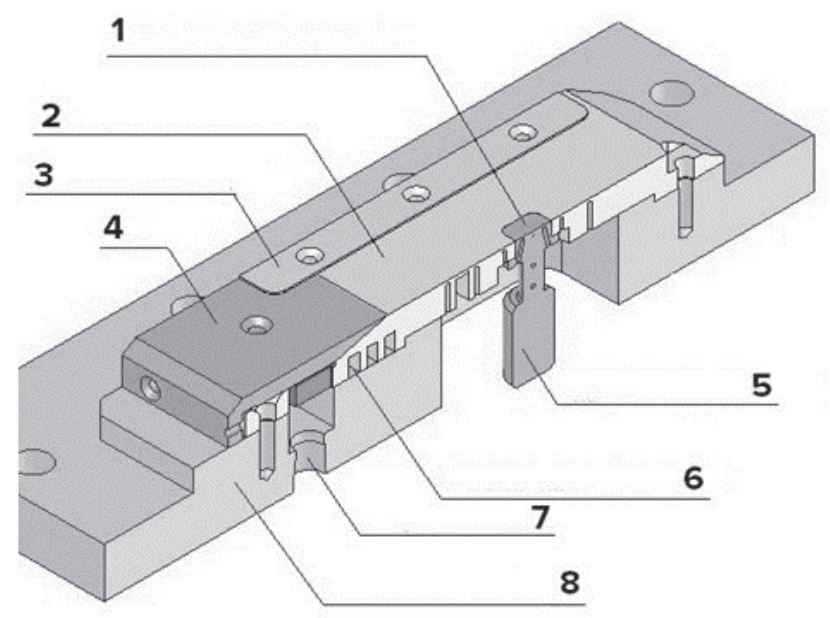

Fig. 1. Design of the working section: 1- source of the local heating; 2- stainless steel plate; 3channel height control; 4- knife; 5- copper rod; 6- thermostabilizer; 7- liquid inlet; 8- textollite substrate.

Gas is fed into the working section by a compressor. Liquid is supplied from the thermostat to the channel through the liquid nozzle and moves under the influence of gas friction over the stainless-steel plate as a film. After passing through the working area, gas flows out to the atmosphere, while liquid returns to the thermostat. Distilled water with the initial temperature of $24^{\circ} \mathrm{C}$ is used as the working liquid. Air with the temperature of 24$27^{\circ} \mathrm{C}$ and relative humidity of $15-30 \%$ is used as the working gas.

Thermocouples embedded into the stainless-steel plate and copper rod allow to determine the temperature of the working surface. The heat flux is determined by electrical power, released by the heating spiral. Thermal conductivity of copper is $400 \mathrm{~W} / \mathrm{mK}$, and this is more than an order higher than that of stainless steel $(15 \mathrm{~W} / \mathrm{mK})$; this ensures moderate heat leakage from the heater into the steel plate. According to the estimate using the measurements of thermocouples embedded into the steel plate, the heat leakages are about $15 \%$ at $\mathrm{q}>200 \mathrm{~W} / \mathrm{cm}^{2}$. To reduce heat losses to the atmosphere, the bottom part of the copper rod was wrapped by a layer of insulating material (not shown in Fig. 1). According to the estimate using the measurements of thermocouples embedded into the rod, heat losses to the atmosphere do not exceed $10 \%$ at $\mathrm{q}>400 \mathrm{~W} / \mathrm{cm}^{2}$. Consequently, the heat leakages and losses in total do not exceed $25 \%$ at q $>400 \mathrm{~W} / \mathrm{cm}^{2}$.

The flow and breakdown of the liquid film is visualized using a high-resolution infrared camera «Titanium HD 570M» (resolution of 640x512 pixels with the frame rate of $115 \mathrm{~Hz}$ ). 
The infrared camera works in the spectral range of $3.7-4.8 \mu \mathrm{m}$, with minimal resolvable temperature difference equivalent to noise (NETD) of $18 \mathrm{mK}$ at $25^{\circ} \mathrm{C}$.

\section{Experimental results}

The behavior of the liquid film moving under the influence of gas was studied in this paper with the values of heat flux $\mathrm{q}=0-1200 \mathrm{~W} / \mathrm{cm}^{2}$, liquid Reynolds number $\mathrm{Re}_{1}=8.5-193$ and superficial gas velocity $\mathrm{U}_{\mathrm{sg}}=3.8-93 \mathrm{~m} / \mathrm{s}$ (gas Reynolds number $\mathrm{Re}_{\mathrm{g}}=150-5960$ ). Figure 2 shows infra-red images illustrating the process of film breaking with increased heat flux at $\mathrm{Re}_{1}=30, \mathrm{U}_{\mathrm{sg}}=22 \mathrm{~m} / \mathrm{s}$. At a certain value of the heat flux, the film breakdown occurs with dry spot formation on the substrate. As a rule, the first dry regions are formed below the heater (not shown in Fig. 2). With an increase of the heat flux, the dry areas reach the heater, and the film on the heater divides into 2-3 nonstationary rivulets (Fig. 2a). With further increase in the heat flux, the heater is covered by a metastable evaporating thin liquid film, with rapidly appearing and disappearing small dry spots (Fig. 2b). When the critical heat flux is achieved, the heater suddenly becomes dry, and the heater temperature starts increasing sharply (Fig. 2c-d).

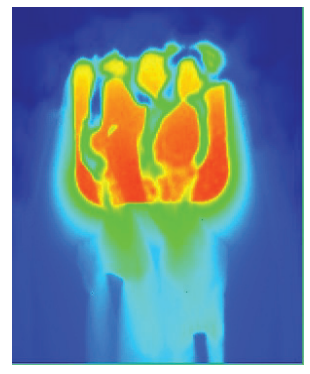

a) $\mathrm{q}=125 \mathrm{~W} / \mathrm{cm}^{2}$, rivulet flow

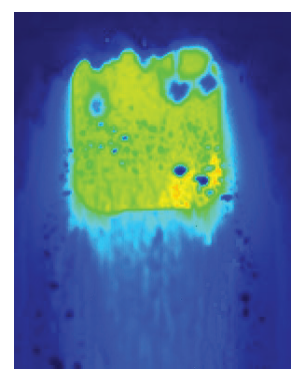

b) $\mathrm{q}=200 \mathrm{~W} / \mathrm{cm}^{2}$, thin film evaporation

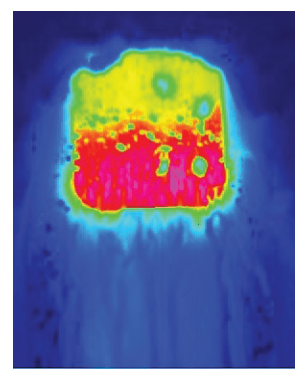

c) $\mathrm{q}=290 \mathrm{~W} / \mathrm{cm}^{2}$, drying out

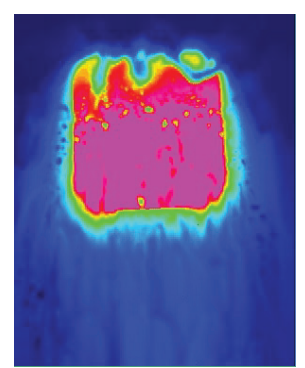

d) $\mathrm{q}=290 \mathrm{~W} / \mathrm{cm}^{2}$, crisis

Fig. 2. Breakdown and crisis in the liquid film moving under the action of gas, heater of $1 \mathrm{x} 1 \mathrm{~cm}^{2}, \operatorname{Re}_{1}$ $=30, \mathrm{U}_{\mathrm{sg}}=22 \mathrm{~m} / \mathrm{s}$, the flow is directed from top to bottom.

Data on the effect of liquid Reynolds number and superficial gas velocity on the critical heat flux are shown in Fig. 3. It is seen that with an increase in the liquid Reynolds number and gas velocity, the critical heat flux increases. The record value of the critical heat flux of $1.2 \mathrm{~kW} / \mathrm{cm}^{2}$ was achieved in experiments (Figure 3, point $\mathrm{Re}_{\mathrm{l}}=193, \mathrm{U}_{\mathrm{sg}}=71.3 \mathrm{~m} / \mathrm{s}$ ). This critical heat flux for the water film flowing under the action of gas was achieved for the mass water flow rate of $175 \mathrm{~kg} / \mathrm{m}^{2} \mathrm{~s}$. At that, as it is shown in [11], the critical heat flux for subcooled water flow boiling in a minichannel (at the same mass flow rate of liquid, at atmospheric pressure and subcooling to the saturation temperature of $75 \mathrm{~K}$ ) reaches 170 $\mathrm{W} / \mathrm{cm}^{2}$ (Fig. 3, line 8). According to [11], to achieve the heat flux of $1.2 \mathrm{~kW} / \mathrm{cm}^{2}$ for water flow boiling in a minichannel, the mass flow rate of liquid should be about $7000 \mathrm{~kg} / \mathrm{m}^{2} \mathrm{~s}$, which is 40 times higher than the mass flow rate in our experiment. 


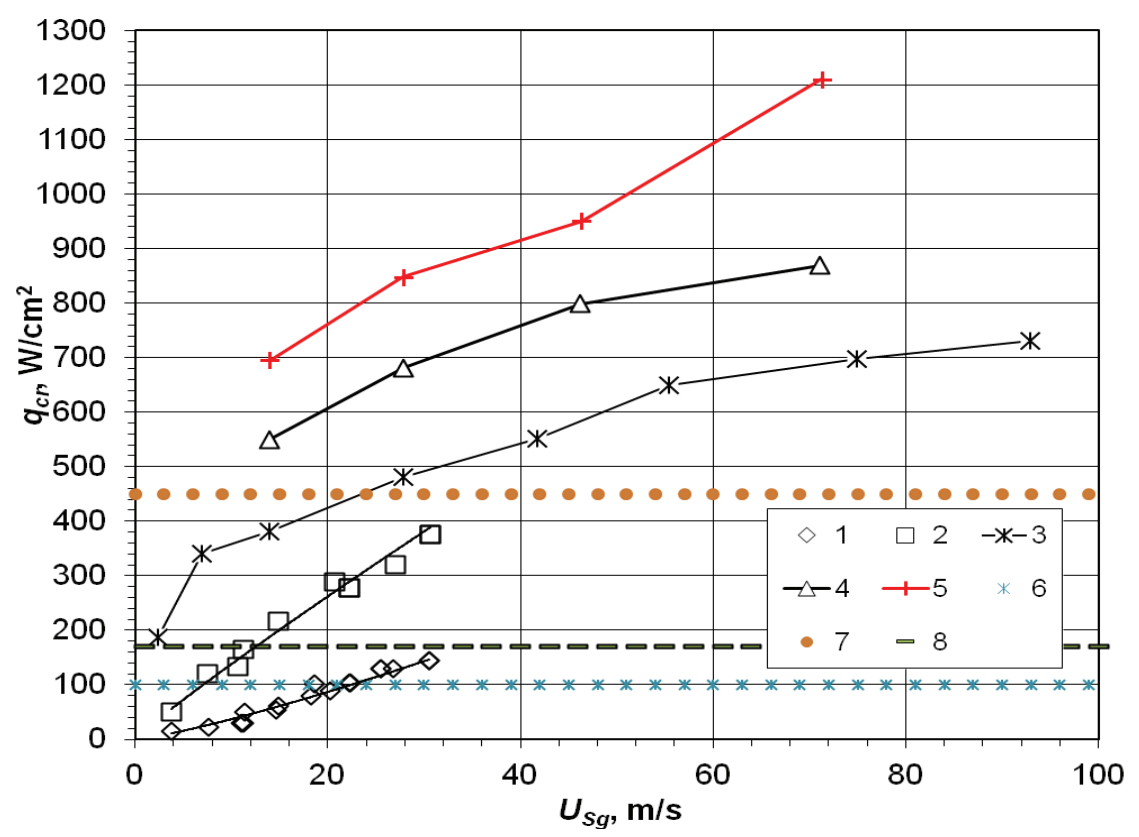

Fig. 3. Critical heat flux vs. superficial gas velocity, Usg, liquid Reynolds number, Rel, and channel height, $\mathrm{H} .1-\mathrm{Re}_{\mathrm{l}}=8.5, \mathrm{H}=1.2 \mathrm{~mm} ; 2-\mathrm{Re}_{\mathrm{l}}=30, \mathrm{H}=1.2 \mathrm{~mm} ; 3-\mathrm{Re}_{\mathrm{l}}=62, \mathrm{H}=1 \mathrm{~mm} ; 4-\mathrm{Re}_{\mathrm{l}}=$ 113, $\mathrm{H}=1 \mathrm{~mm} ; 5-\mathrm{Re}_{1}=193, \mathrm{H}=1 \mathrm{~mm} ; 6$ - water pool boiling (formula of Kutateladze $\left.q_{c r}=0.14 r \sqrt{\rho_{v}} \sqrt[4]{\sigma g\left(\rho_{1}-\rho_{v}\right)},[10]\right) ; 7-$ water pool boiling at subcooling to the saturation temperature of $75 \mathrm{~K}[10]$; 8 - water flow boiling in a mini-channel for mass flow rate $175 \mathrm{~kg} / \mathrm{m}^{2} \mathrm{~s}$, at atmospheric pressure and subcooling to the saturation temperature of $75 \mathrm{~K}$ [11].

\section{Conclusions}

The critical heat flux for the water films moving under the influence of gas flow friction in a minichannel can reach $1.2 \mathrm{~W} / \mathrm{cm}^{2}$, which is an order of magnitude higher than the critical heat flux for water flow boiling (for the same mass flow rate, same subcooling to the saturation temperature, and same pressure). Heat losses to the atmosphere and heat leakages to the substrate in our experiments in total do not exceed $25 \%$ at heat fluxes higher than 400 $\mathrm{W} / \mathrm{cm}^{2}$. The results obtained confirm the prospects of the use of shear-driven liquid films in the modern cooling systems for devices with high local heat release.

The work was performed under the support of Russian Science Foundation (project № 14-19-01755).

\section{References}

1. A. Bar-Cohen, C. Holloway. Journal of Physics: Conference Series, 745, 022002 (2016)

2. O.A. Kabov, Yu.V. Lyulin, I.V. Marchuk and D.V. Zaitsev. International Journal of Heat and Fluid Flow, 28, 103-112 (2007)

3. E. Ya. Gatapova and O. A. Kabov. International Journal of Heat and Mass Transfer, 51, 4797-4810 (2008)

4. Y. Kabova, O. Kabov, T. Gambaryan-Roisman, P. Stephan and V. V. Kuznetsov. International Journal of Heat and Mass Transfer, 68, 527-541 (2014) 
5. D. V. Zaitsev, D. A. Rodionov and O. A. Kabov. Technical Physics Letters, 35, 680682 (2009)

6. O. A. Kabov and D. V. Zaitsev. Multiphase Science and Technology, 21, 249-266 (2009)

7. O.A. Kabov, D.V. Zaitsev, V.V. Cheverda, A. Bar-Cohen. Experimental Thermal and Fluid Science, 35, 825 (2011)

8. V. S. Ajaev. Interfacial Phenomena and Heat Transfer, 1, 81-92 (2013)

9. M. Kadoura and S. Chandra. Experiments in Fluids, 54, 1-11 (2013)

10. S.S. Kutateladze, Heat Transfer in Condensation and Boiling (Mashgiz, Moscow, 1952)

11. W. Zhang, T. Hibiki, K. Mishima, Y. Mi, International Journal of Heat and Mass Transfer, 49, 1058-1072 (2006) 